\title{
ИССЛЕДОВАТЕЛЬСКАЯ И ПРАКТИЧЕСКАЯ ПСИХОЛОГИЯ В РОССИИ В ПЕРИОДЫ МИРОВЫХ ВОЙН ХХ ВЕКА*
}

\author{
O. А. Артемьева \\ Иркутский государственный университет
}

\begin{abstract}
Аннотация: В статье обсуждаются результаты сравнительного исследования взаимоотношений исследовательской и практической психологии в России в периоды Первой мировой и Великой Отечественной войн.

По материалам научного доклада на конференции «Кросс-культурные и междисциплинарные исследования в истории психологии: результаты и перспективы» (Москва, 24-25 ноября 2018 г.), проведенной в рамках проекта № 18-513-18017, поддержанного РФФИ.
\end{abstract}

Ключевые слова: история психологии; преподавание истории психологии; историко-психологические исследования; кафедра психологии; образовательный стандарт; Московский гуманитарный университет

\section{RESEARCH AND PRACTICAL PSYCHOLOGY IN RUSSIA DURING THE PERIODS OF THE 20th CENTURY WORLD WARS}

\author{
O. A. Artemyeva \\ Irkutsk State University
}

\begin{abstract}
The paper discusses the results of a comparative research into the relationship between research and practical psychology in Russia during the periods of the First World War and the Great Patriotic War.

The research is based on the materials of the scientific report at the conference "CrossCultural and Interdisciplinary Studies into the History of Psychology: Results and Prospects" (Moscow, 24-25 November 2018), held within the project No. 18-513-18017 supported by RFBR.

Keywords: The paper discusses the results of a comparative research into the relationship between research and practical psychology in Russia during the periods of the First World War and the Great Patriotic War
\end{abstract}

\footnotetext{
* Работа подготовлена при поддержке гранта РФФИ № 17-36-01096.

The research is conducted with financial support of the Russian Fundation for Basic Research, grant № 17-36-01096.
} 
Научные труды Московского гуманитарного университета

2019 № 1

\section{Введение}

Одной из современных тенденций разработки проблем истории психологии является внимание к практике работы психологов в годы Второй мировой войны. Примером могут служить не только отдельные исследовательские проекты российских, американских и германских ученых В. А. Кольцовой, Ю. Н. Олейника, А. Р. и К. К. Джилджен, У. Гётера, М. Аша, М. Визера и др. (Психологическая наука в России XX столетия..., 1997; Кольцова, Олейник, 2006; Gilgen et al., 1997; Geuter, 1988; Ash, 2002; Wieser; 2018), но и научные конференции, проведенные при поддержке Российского фонда фундаментальных исследований в 2018 г. в России и Болгарии.

Важным ракурсом анализа этой проблемы является изучение особенностей и результатов развития исследовательской и практической психологии в условиях мировой войны. Трагическая история прошлого века предоставляет возможности сравнительных исследований закономерностей и итогов решения вопросов и задач психологической науки и практики в периоды Первой и Второй мировых войн.

Экстремальные условия военного времени актуализируют тенденции, недостаточно очевидные при обращении к истории науки в периоды стабильности. Одним из важных аспектов развития психологии, обнаруживающим себя более выпукло в годы войны, являются взаимоотношения исследовательской и практической психологии. Эта проблема находится в фокусе внимания современных исследователей (Артемьева, 2015а; Богданчиков, 2015; Гусельцева, 2015; Журавлев, Ушаков, 2015; Юревич, 2015 и др.). Рассмотрим возможности ее решения на историко-психологическом материале публикационной активности отечественных психологов в периоды мировых войн XX века.

В ходе сравнительного анализа влияния обеих войн на развитие исследовательской и практической психологии в России нами проведен качественный и количественный анализ публикаций ведущих отечественных психологов, изданных в течение пяти лет каждой из войн, а также в предшествующие и последующие пятилетия (Артемьева, 2015b). По итогам анализа учебных пособий по истории психологии, данных цитирования в современных научных работах по психологии, экспертной оценки и анализа библиографических списков научных работ психологов к ним отнесены: Б. Г. Ананьев, М. Я. Басов, В. М. Бехтерев, П. П. Блонский, Л. И. Божович, В. А. Вагнер, А. Б. Залкинд, А. В. Запорожец, К. Н. Корнилов, А. Ф. Лазурский, Н. Н. Ланге, А. Н. Леонтьев, А. Р. Лурия, В. Н. Мясищев, А. П. Нечаев, К. К. Платонов, С. Л. Рубинштейн, Н. А. Рыбников, А. А. Смирнов, И. В. Страхов, Б. М. Теплов, Г. И. Челпанов, Г. Г. Шпет. Всего в анализе участвовало 606 публикаций 23 ведущих психологов. Из них 12 ученых публиковали работы в период 
Первой мировой войны и 12 ученых - в период Великой Отечественной войны; К. Н. Корнилов вошел в число ведущих психологов, активно издававших научные и научно-популярные работы на протяжении обоих периодов.

\section{Итоги Первой мировой войны}

Для изучения результатов деятельности русских психологов в период Первой мировой войны проанализировано 386 заголовков книг и статей 12 ведущих психологов этого периода: М. Я. Басова, В. М. Бехтерева, П. П. Блонского, В. А. Вагнера, А. Б. Залкинда, К. Н. Корнилова, А. Ф. Лазурского, Н. Н. Ланге, А. П. Нечаева, Н. А. Рыбникова, Г. И. Челпанова, Г. Г. Шпета.

Полученные данные обнаруживают увеличение количества научных публикаций психологов во время войны: с 124 работ в довоенный период до 161. Данная тенденция характерна для научной деятельности Г. Г. Шпета, П. П. Блонского, Н. А. Рыбникова - военные годы стали для них временем плодотворной научной деятельности. Очевидно, большее значение для публикационной активности имели не социальные, а личностные детерминанты. В частности, Г. Г. Шпет в 1910-1913 гг. стажировался в нескольких университетах - прежде всего Геттингенском, а также Берлинском, Эдинбургском и Парижском. Вдохновленный идеями немецкого философа Э. Гуссерля, в военный 1914 г. он опубликовал в России работу «Явление и смысл», посвященную феноменологии. А в 1916 г., в развитие этих идей, защитил диссертацию «История как проблема логики».

В судьбах других молодых ученых Н. А. Рыбникова и П. П. Блонского значительную роль сыграла работа под руководством отечественного философа и психолога Г. И. Челпанова. Благодаря этому ученому оба стали аспирантами основанного в 1912 г. Психологического института. П. П. Блонский для этого переехал в Москву из Киева. Таким образом, активная научная деятельность названных психологов даже в годы войны была закономерна для молодых ученых 30-35 лет, получивших передовое для Европы образование и возможность научных исследований.

Еще большего внимания заслуживает факт значительного снижения числа психологических публикаций уже после войны до 101 работы. Это можно объяснить ограничением финансирования научных изданий. Вместе с тем, результаты проведенного анализа свидетельствуют о том, что в военные годы продолжали выходить из печати журналы «Вестник психологии, криминальной антропологии и педологии», «Вопросы философии и психологии» и др. Ситуация изменилась после 1917 г., когда с революционной сменой правительства и общественного строя началось оформление нового социального заказа.

Октябрьская революция стала решающим фактором, определившим 
Научные труды Московского гуманитарного университета 2019 № 1

содержание послевоенных публикаций. Особенностью психологических работ была ориентация на запросы нового государства, воспитание и изучение нового человека. Революционные преобразования в определенной степени стимулировали разработку психологических проблем педагогики и педологии. В первые послереволюционные годы им был посвящен значительный объем публикаций П. П. Блонского, К. Н. Корнилова и др. Откликом на социальный заказ стали работы по обоснованию марксистских материалистический основ психологии, прежде всего К. Н. Корнилова.

Молодое советское государство нуждалось в новой идеологии. От ученых ожидали не столько осмысления прошлого, сколько построения нового. В этих условиях обращение к опыту военных действий было востребовано лишь в контексте решения задач Красной Армии. Это подтверждают результаты качественного анализа заголовков публикаций, свидетельствующие о влиянии войны лишь на тематику работ А. П. Нечаева. В период с 1922 по 1924 гг. он опубликовал не менее четырех статей: «К вопросу о применении экспериментально-психологических методов к выяснению проблем, связанных с техникой военного дела» (1922), «К вопросу об организации библиотечного дела в Красной армии (Наблюдения над умственным развитием красноармейцев)» (1922), «К вопросу об экспериментально-психологическом исследовании летчиков» (1923), «Психологические наблюдения над учащимися в военно-учебных заведениях» (1924). В этих работах А. П. Нечаева военная деятельность и подготовка предстали как области применения развиваемых им экспериментально-психологических методов. Таким образом, условия военного времени оказали влияние на решение исследовательских задач прикладного характера. Хотя в годы мировой и гражданской войн начала активно развиваться военная психология (Дьяченко, 1985), ее проблемы все же выходили за рамки научных интересов большинства ведущих отечественных психологов.

В целом, результаты анализа работ ведущих отечественных психологов 1909-1923 гг. позволяют сделать следующие выводы. Объем психологических публикаций в ходе Первой мировой войны повысился. Для части ученых военные годы стали временем активной научной деятельности. Участие России в войне 1914-1918 гг. определило развитие отечественной военной психологии, но лишь в незначительной степени сказалось на тематике психологических исследований ведущих отечественных психологов во время и непосредственно после войны. Их наиболее известные достижения были связаны с исследовательской, а не практической деятельностью. Первая мировая война повлияла на отечественную психологию, прежде всего, своими последствиями. В качестве решающего дополнительного фактора социально-исторической детерминации научного познания выступила 
Октябрьская революция 1917 г. В результате произошедшего переворота изменился социальный заказ в отношении психологической науки. Востребованность научных работ по построению новой психологии сказалась на выборе психологами основного направления исследований и их эмпирического материала.

\section{Достижения психологии в годы Великой Отечественной войны}

С целью изучения влияния Второй мировой войны, сказавшейся на истории русской психологии непосредственно в годы Великой Отечественной войны, был проведен анализ заголовков 320 публикаций 12 ведущих советских психологов за период с 1936 по 1950 гг. Это работы Б. Г. Ананьева, Л. И. Божович, А. В. Запорожца, К. Н. Корнилова, А. Н. Леонтьева, А. Р. Лурии, В. Н. Мясищева, К. К. Платонова, С. Л. Рубинштейна, А. А. Смирнова, И. В. Страхова, Б. М. Теплова.

Обнаружено относительное увеличение числа работ в военный период: в то время, как за пять довоенных лет авторами опубликовано не менее 80 работ, в военный период - не менее 90 . Значительный рост числа изданных работ приходится на послевоенный период: обнаружено 180 публикаций. Полученные данные позволяют говорить о положительной динамике числа публикаций и развитии психологической теории и практики под влиянием военных действий 1941-1945 гг.

Наиболее показателен рост числа публикаций Б. Г. Ананьева и Б. М. Теплова: в предвоенное пятилетие ими были опубликованы 12 и 9 работ соответственно, во время войны - 17 и 12, после войны - 36 и 21 работа. Анализ содержания публикаций позволяет говорить о том, что увеличение их количества произошло за счет обращения к опыту психологического сопровождения военных действий. И Б. Г. Ананьев, и Б. М. Теплов продолжили исследования, начатые накануне войны, но большее развитие в их работах получили вопросы прикладной психологии военного времени. Показательна работа «Ум и воля военачальника» (1943) Б. М. Теплова. Особый интерес представляет его статья «Бунт звериного инстинкта против человеческого разума (фашистская психология Йенша)» (1941). В ней, как и в работах Б. Г. Ананьева, С. Л. Рубинштейна и др., содержится критика расистских идей, призванных оправдать претензии фашистских идеологов на превосходство «арийской расы».

Б. Г. Ананьев в годы войны был начальником психологического кабинета эвакогоспиталя в г. Тбилиси, занимался восстановлением психических функций раненых бойцов. Результаты этой практической работы и основанных на ее материале исследований представлены в работах «0 психокортикальном восстановлении при боевых травмах мозга» (1942), «Некото- 
Научные труды Московского гуманитарного университета

2019 № 1

рые вопросы восстановительной терапии после ранений головного мозга» (1943) и др. Важно заметить, что хотя практико-ориентированные военные работы Б. М. Теплова и Б. Г. Ананьева были откликом на социальный заказ военного времени, они не состоялись бы без исследовательского опыта, накопленного авторами в этих областях в довоенный период.

Рост объема публикаций учеников Л. С. Выготского - А. Р. Лурии, А. Н. Леонтьева и А. В. Запорожца - также можно объяснить имевшимся у них опытом совместной психоневрологической деятельности. Он пригодился при организации практической помощи - восстановительной работы в госпиталях близ Свердловска.

Снижение объема публикаций таких ученых, как В.Н. Мясищев, А. А. Смирнов, И. В. Страхов во время войны и его увеличение в послевоенный период может быть объяснено материальными возможностями науки военного и послевоенного периодов. Так, исследовательская работа В. Н. Мясищева в 1941-1944 гг. проходила в блокадном Ленинграде. Военный опыт исследования мозговых травм, реактивных состояний и т. д. позволил ученому уточнить знания о соотношениях психогенных и физиогенных факторов невропсихопатологии. В эти годы В. Н. Мясищевым была завершена и защищена докторская диссертация «Электрокожные показатели нервно-психических состояний человека» (1944).

В годы Великой Отечественной войны активно развивалась военная психология. В разработке разных аспектов военного дела участвовали ведущие психологи страны. Приобрели известность психологические работы по военной маскировке Б. Г. Ананьева, Б. М. Теплова, С. В. Кравкова. Д. Б. Эльконин исследовал психологические основы стрельбы. Борьба с врагом в условиях войны стала фактором предельной мобилизации и концентрации всех ресурсов страны, духовного и интеллектуального потенциала (Кольцова, Олейник, 2006).

Продолжились фундаментальные психологические исследования. В эвакуации работали сотрудники Ленинградского института мозга им. В. М. Бехтерева, Ленинградского педагогического института им. А. И. Герцена, Московского института психологии. Во время войны реализовался значительный организаторский потенциал ведущих ученых страны: Б. Г. Ананьева, А. Н. Леонтьева, С. Л. Рубинштейна и др.

В этот период потерь и лишений были открыты новые научно-исследовательские центры: лаборатория экспериментальной психологии Тбилисского государственного университета, научно-исследовательский институт психологии в г. Киеве, лаборатория по изучению речи при Ленинградском государственном педагогическом институте им. А. И. Герцена. В 1943 г. была организована Академия педагогических наук с педагогическим и психоло- 
гическим отделениями, в 1945 г. - сектор психологии при АН СССР.

Трагические условия войны дали толчок развитию психологического образования. В 1943 и 1944 гг. в Московском и Ленинградском университетах открылись психологические кафедры и отделения. И опять же, создание новых исследовательских и образовательных центров психологии стало возможным не только в силу социального запроса, но и наличия кадров, способных обеспечить качественное психологическое образование. Советская психология на тот момент представляла собой достаточно зрелую область знания, представители которой имели фундаментальное, в том числе дореволюционное, образование, навыки эмпирических исследований и философского анализа научных проблем, опыт участия в активных научных дискуссиях (Артемьева, 2018).

В условиях военного противостояния государств оказались востребованы работы по истории России, способствующие развитию положительной социальной идентичности, национального самосознания. В 1945-1948 гг. Б. Г. Ананьев, Б. М. Теплов и др. представили психологическое наследие национальных общественных деятелей К. Д. Ушинского, В. Г. Белинского, И. М. Сеченова и др. В 1941-1943 гг. Б. Г. Ананьев, А. Н. Рыбников и С. Л. Рубинштейн опубликовали ряд работ, посвященных истории отечественной психологии, выделению ее специфики, методологических основ исследования.

В послевоенный период 1946-1950 гг. количество публикаций ведущих советских психологов возросло в два раза. Анализ содержания их работ свидетельствует о том, что не менее 20 публикаций стали результатом исследований по военной тематике. Значительная часть работ посвящена вопросам восстановления психических функций, реабилитации после полученных травм. Среди них не только статьи, но и монографии, в частности работа А. Р. Лурии «Восстановление функций мозга после военной травмы» (1948), в которой автор представил основы будущей нейропсихологии. Вместе с тем необходимо отметить послевоенный прогресс в развитии психологической науки в целом. Вышло второе издание «Основ общей психологии» С. Л. Рубинштейна (1946), работу над которым он продолжал даже во время эвакуации в Ленинграде. Опубликованы монографии Б. М. Теплова «Психология музыкальных способностей» (1947), А. А. Смирнова «Психология запоминания» (1948) и др.

Таким образом, Вторая мировая война способствовала развитию отечественной психологии. В большей степени она стимулировала прикладные исследования, прежде всего, в области восстановления психических функций и реабилитации раненых бойцов. Результаты работы созданных в ее годы реабилитационных и научно-исследовательских центров были осмыслены и обобщены в научных монографиях, стали материалом для разработ- 
Научные труды Московского гуманитарного университета 2019 № 1

ки фундаментальных основ психологии, а также способствовали рождению новой научной области - нейропсихологии.

В целом, Великая Отечественная война способствовала развитию как практики психологической помощи, так и основанных на ее материале прикладных научных исследований. Каждый ученый и научное сообщество в целом, все общество работали для фронта и победы. Успешная работа психологов привела к укреплению авторитета психологической науки в целом. Не прервались и фундаментальные исследования.

Несмотря на относительно более высокий рост числа обнаруженных работ в ходе Первой Мировой войны, их содержание в меньшей степени отражает влияние военного времени. Если итогом Первой Мировой и гражданской войн были статьи отдельных авторов по военной психологии, то результатом осмысления опыта деятельности психологического сообщества в годы Великой Отечественной войны явилась подготовка целого ряда работ, освещающих результаты и достижения советских психологов последнего десятилетия, развития военной психологии как самостоятельного направления психологии, актуальное состояние психологической теории и практики.

Проведенное исследование позволяет говорить о влиянии мировых войн на развитие как психологии в России. Однако результаты влияния обеих войн на деятельность ведущих отечественных психологов было неравнозначно. Качественный и сленговый анализ заголовков работ, опубликованных исследователями в 1914-1918 гг., не позволил обнаружить следы их участия в решении практических задач военного времени. В то время как результаты анализа заголовков работ ведущих психологов в годы Первой мировой войны свидетельствуют о значительном внимании авторов к разным практическим аспектам военной психологии и реабилитации раненых.

На годы обеих войн приходятся достижения в фундаментальной исследовательской психологии: известны случаи публичной защиты диссертаций, издания монографий, подготовленных на материале военных лет. Однако в годы Первой мировой войны эти события происходили словно параллельно с участием страны в мировой войне. Если результатом Первой мировой и гражданской войн были статьи отдельных авторов по военной психологии, то в свете задач Великой Отечественной войны был подготовлен целый ряд работ, освещающих актуальное состояние психологической теории и практики, результаты и достижения советских психологов последнего десятилетия. Не обнаружены следы зависимости внимания к научному наследию и оценки идей авторов от их принадлежности к стране-противнику в войне 1914-1918 гг. И иначе, в преддверии и во время Второй мировой войны оценивались идеи фашистских психологов-идеологов в 1930-1940-х гг. 
Успехи как практической, так и исследовательской - прикладной и фундаментальной - психологии 1940-х годов в послевоенный период стали возможны благодаря сплочению отечественных психологов в деле построения самобытной марксистской психологии и организации обороны Родины. В экстремальных условиях Великой Отечественной войны психологическое сообщество обнаружило способность к самоорганизации (Артемьева, 2012), собственному преобразованию, вызвавшему конструктивные изменения условий их жизни и деятельности. Опыт активной исследовательской работы, осмысления закономерностей функционирования психического способствовал усилению дисциплинарной организации советской психологической науки и сохранению ее теоретической независимости в период Павловской сессии (Артемьева, 2015).

Сообщество ученых откликнулось не только на социальный заказ, но и общественную потребность. Совместный опыт решения задач построения советской психологии, обеспечения нужд фронта и тыла, историко-научная рефлексия ведущих представителей научного сообщества определили успехи прикладной и практической психологии. В свою очередь, фактологический материал, накопленный и систематизированный в годы оборонительных и освободительных военных действий 1941-1945 гг., стал основой для развития существующих и разработки новых направлений фундаментальной психологии.

\section{СПИСОК ЛИТЕРАТУРЫ}

Артемьева, О. А. (2012) К проблеме управления и самоорганизации отечественной психологической науки в первой половине XX столетия // Известия Иркутского государственного университета. Серия «Психология». Т. 1. № 2. С. 28-35.

Артемьева, 0. А. (2015а) Предыстория «диагонального разрыва»: уроки социальной истории психоанализа, педологии и психотехники в России столетия // Взаимоотношения исследовательской и практической психологии / под ред. А. Л. Журавлева, А. В. Юревича. М. : Изд-во «Институт психологии РАН». С. 311-336.

Артемьева, 0. А. (2015b) Социально-психологическая детерминация развития российской психологии в первой половине XX столетия. М. : Издво «Институт психологии РАН». 534 с.

Артемьева, О. А. (2018) Научные и идеологические дискуссии в формировании методологического единства советской психологии // Методология и история психологии. Вып. 2. С. 73-88.

Богданчиков, С.А. (2015) Советская исследовательская и практическая психология // Взаимоотношения исследовательской и практической пси- 
хологии / под ред. А. Л. Журавлева, А. В. Юревича. М. : Изд-во «Институт психологии РАН». С. 337-384.

Гусельцева, М.С. (2015) Культурно-деятельностная эпистемология как основание интеграции исследовательской и практической психологии // Взаимоотношения исследовательской и практической психологии / под ред. А. Л. Журавлева, А. В. Юревича. М. : Изд-во «Институт психологии РАН». С. 179-213.

Дьяченко, М. И. (1985) Советская психологическая наука на службе обороны Родины // Вопросы психологии. № 3. С. 5-13.

Журавлев, А. Л., Ушаков, Д. В. (2015) Пути и принципы взаимодействия теоретико-экспериментальной психологии и практики // Взаимоотношения исследовательской и практической психологии / под ред. А. Л. Журавлева, А. В. Юревича. М. : Изд-во «Институт психологии РАН». С. 18-69.

Кольцова, В. А., Олейник, Ю.Н.(2006) Советская психологическая наука в годы Великой Отечественной войны (1941-1945). М. : Изд-во Моск. гуманитар. ун-та, Ин-т психологии РАН. 360 с.

Психологическая наука в России XX столетия: Проблемы теории и истории (1997) / под ред. А. В. Брушлинского. М. : Изд-во «Институт психологии $\mathrm{PAH».} 574 \mathrm{c}$.

Юревич, А.В. (2015) Еще раз о «схизисе» исследовательской и практической психологии // Взаимоотношения исследовательской и практической психологии / под ред. А. Л. Журавлева, А. В. Юревича. М. : Изд-во «Институт психологии РАН». С. 70-90.

Ash, M. (2002) Die Rolle der Geisteswissenschaften im Dritten Reich 19331945 // Psychology / Ed. by A. Hausmann. P. 229-264.

Geuter, U. (1988) The professionalization of Psychology in Nazi Germany. Cambridge: Cambridge University Press. 360 p.

Gilgen, A.R., Gilgen, C. K., Koltsova, V. A., Oleinik Y. N. (1997) Soviet and American Psychology During World War II. Westport-London: Greenwood Press. $242 \mathrm{p}$.

Wieser, M. (2018) Psychology in the "Ostmark": Applied Psychology in times of war // ESHHS Groningen: Book of Abstracts / Ed. J. Eshuis. Netherlands: Open University of Netherlands. P. 19-20.

Дата поступления: 15.01.2019.

Артемьева Ольга Аркадьевна - доктор психологических наук, доцент, профессор кафедры социальной, экстремальной и пенитенциарной психологии, Иркутский государственный университет, член Европейского общества истории гуманитарных наук, Российского психологического об- 
щества, член-корреспондент Международной академии психологических наук. Адрес: 664025, Россия, г. Иркутск, ул. Чкалова, 2, каб. 406. Тел.: +7 (3952) 20-23-49. Эл. адрес: artemeva@yandex.ru

Artemeva Olga Arkadjevna, Doctor of Sciences (Psychology), Docent, Professor of the Chair of Social, Extremal, and Penitential Psychology, member of the European Society for the History of Human Sciences, the Russian Psychological Society, corresponding member of the International Academy of Psychological Sciences. Postal address: 406, 2, Chkalova, Irkutsk, 664025, Russia. Tel.: +7 (3952) 20-23-49. E-mail: oaartemeva@yandex.ru

\section{Для цитирования:}

Артемьева О. А. Исследовательская и практическая психология в России в периоды мировых войн XX века [Электронный ресурс] // Научные труды Московского гуманитарного университета. 2019. № 1. URL: http://journals. mosgu.ru/trudy/article/view/942(дата обращения: дд.мм.гг.). DOI: 10.17805/ trudy.2019.1.3 